\title{
Correction to: Image quality of ultralow-dose chest CT using deep learning techniques: potential superiority of vendor-agnostic post-processing over vendor-specific techniques
}

\author{
Ju Gang Nam ${ }^{1}$. Chulkyun Ahn ${ }^{2}$ • Hyewon Choi ${ }^{1}$ • Wonju Hong ${ }^{1} \cdot$ Jongsoo Park ${ }^{1}$. Jong Hyo Kim ${ }^{1,2,3}$ • Jin Mo Goo ${ }^{1,4}$ (D) \\ Published online: 15 February 2021 \\ (C) European Society of Radiology 2021
}

\section{Correction to: European Radiology}

https://doi.org/10.1007/s00330-020-07537-7

The original version of this article, published on 07 January 2021, unfortunately contained a mistake. The following correction has therefore been made in the original: The information that Ju Gang Nam and Chulkyun Ahn contributed equally to this work was missing. The original article has been corrected.

Publisher's note Springer Nature remains neutral with regard to jurisdictional claims in published maps and institutional affiliations.

Ju Gang Nam and Chulkyun Ahn contributed equally to this work.

The online version of the original article can be found at https://oi.org/ 10.1007/s00330-020-07537-7

\section{Jin Mo Goo}

jmgoo@plaza.snu.ac.kr

1 Department of Radiology, Seoul National University College of Medicine, and Institute of Radiation Medicine, Seoul National University Medical Research Center, 101 Daehak-ro, Jongno-gu, Seoul 03080, South Korea

2 Department of Transdisciplinary Studies, Program in Biomedical Radiation Sciences, Graduate School of Convergence Science and Technology, Seoul National University, Seoul 08826, South Korea

3 Center for Medical-IT Convergence Technology Research, Advanced Institutes of Convergence Technology, Suwon 16229, South Korea

4 Cancer Research Institute, Seoul National University, Seoul 03080, South Korea 